\title{
O PROCESSO DE METROPOLIZAÇÃO DO ESPAÇO NO RIO DE JANEIRO: A (RE) PRODUÇÃO DE UM MODELO PORTUÁRIO PARA POUCOS
}

\author{
Maria Luíza Silva ${ }^{12}$ \\ luiza_mls15@hotmail.com \\ Universidade do Estado do Rio de Janeiro - UERJ \\ Faculdade de Educação da Baixada Fluminense - FEBF
}

\section{Resumo:}

Tomando como pano de fundo o processo de reproduções lógicas e estratégias da atual fase do capitalismo, o artigo procura compreender os impactos gerados por este fenômeno que afeta não somente a esfera econômica, mas também a produção do espaço urbano, atingindo diretamente sua formulação e legitimação perante as políticas públicas. Diante disso, procura-se analisar tal processo dentro da dinâmica da cidade do Rio de Janeiro através do projeto de reforma urbana proposto para a zona portuária, intitulado de Porto Maravilha, procurando analisar os procedimentos materiais e simbólicos, tomados como estratégias, envolvidos nesse processo, ao mesmo tempo em que esses nos apontam os benefícios que são e serão gerados para o grande capital através da mercadificação dos espaços urbanos que permite ao capital privado ditar as regras, gerando acentuada segregação espacial.

Palavras-chaves: metropolização do espaço - zonas portuárias- injustiça social.

\footnotetext{
${ }^{1} \mathrm{O}$ artigo é fruto da pesquisa intitulada "O processo de Metropolização Espaço no Rio de Janeiro: entre Renovações, "Revitalizações" e (I) Mobilizações". Orientador: Alvaro Ferreira (UERJ/PUC RIO).

${ }^{2}$ Artigo apresentado no XIII Simpósio Nacional de Geografia Urbana.
} 


\section{Zona Portuária do Rio de Janeiro e a lógica de "padronização" portuária}

A Zona Portuária do Rio de Janeiro é composta pelos bairros da Saúde, Gamboa, Santo Cristo e Caju, durante todo o processo de adensamento e urbanização da cidade do Rio de Janeiro esta área foi de extrema importância estratégica, visto que até o início do século XVIII a cidade se restringia a área envolvida pelo chamado "Centro do Rio" e sua zona periférica.

Porém, fatores político-econômicos levaram a um desinteresse dessa área devido à perda de importância da atividade portuária, permitindo assim, cair no esquecimento e em um profundo processo de degradação até atualmente. Ao mesmo tempo em que se encontra em estado de penúria, a Zona Portuária não perdeu seu caráter estratégico com relação à facilidade de transportes e por se situar próxima ao centro econômico da cidade.

A partir dessa dinâmica, a Zona Portuária do Rio de Janeiro passa a ser vista como um espaço em potencial para o modelo urbanístico adotado, que aponta a revitalização urbana como uma possível oportunidade de alavancar a dinâmicas imobiliárias associadas dominação espacial e reprodução do capital.

Para compreender os conceitos que norteiam a discussão no que tange ao modelo de urbanização implementado na cidade do Rio de Janeiro é necessário um melhor entendimento desse modelo de urbanização, onde se ressalta que atualmente a centralidade das cidades se expressa pelo fato delas ainda serem o instrumento de acumulação e locus da reprodução do capital, portanto espaço privilegiado para a globalização. Deste modo, as cidades ganham valor como espaço concentrador de poder, redefinindo os seus espaços e adquirindo um novo papel: a mercadoria.

Sendo as cidades mercadorias a serem vendidas, caberia ao Estado criar as condições necessárias para sua inserção econômica nos fluxos globais. Para tanto, este agente busca desenvolver uma agenda de transformações que engloba a adoção do chamado planejamento estratégico. Assim: 
Figuras de linguagem como 'orientação para a demanda', 'atrativos da oferta urbana', 'posicionamento competitivo', 'ações de marketing', 'produção de imagem' e 'planejamento estratégico', que até há pouco tempo eram restritas ao âmbito empresarial, hoje são recorrentes no discurso e nos instrumentos utilizados para o planejamento e gestão das cidades por parte de administrações locais (SÁNCHEZ, 2003, p.175).

Sob esta ótica do planejamento estratégico, onde as cidades são vistas como empresas e mercadorias ao mesmo tempo, também se faz necessário constituir um arcabouço ideológico de imagem da cidade, originando, assim, as chamadas "cidades-modelos" que, segundo Sánchez (2001):

São imagens de marca construídas pela ação combinada de governos locais, junto a atores hegemônicos com interesses localizados para a elaboração um complexo mercado no qual as imagens são construídas e postas em circulação em variadas escalas (local, nacional e internacional), com mútuas influências de diversa ordem (SÁNCHEZ, 2001, p.32).

Como instrumento de consolidação desse modelo, são desenvolvidas políticas de promoção e legitimação de certos projetos de cidade. Esses projetos são difundidos como emblemas da época presente. Sua imagem publicitária, as chamadas "cidades-modelo", e seus pontos de irradiação são difundidos pelas instâncias políticas de produção de discursos: governos locais em associação com as mídias; e instituições supranacionais (SÁNCHEZ, 2001). Uma das maneiras de difusão dos chamados "modelos" se deu através das intervenções urbanas em áreas portuárias centrais, propondo investimentos para a ocupação dos vazios urbanos e a requalificação dos espaços. As transformações nas zonas portuárias das cidades tornou-se um novo modelo para o desenvolvimento urbano através do discurso de revitalização das áreas centrais. Logo, é importante entender a respeito dos chamados "modelos" que iriam influenciar as políticas urbanas do Brasil, em especial do Rio de Janeiro.

O sucateamento dos tradicionais portos, agregado a isso a queda das atividades industriais próximas às áreas portuárias tradicionais, em geral localizadas na área central das cidades, acabaram por deixar ociosas grandes extensões de terra muito bem localizadas e bem servidas de infraestrutura urbana (FERREIRA, 2011). Tais características justificaram o discurso da 
revitalização das áreas centrais, promovendo novos espaços para o mercado. Dentre as cidades que passaram por esse tipo de revitalização, destacam-se as grandes obras na frente marítima de Boston e no porto de Baltimore, onde Ferreira (2011) ainda ressalta os grandes investimentos no intuito de transformar essas áreas abandonadas em locais propícios para alavancar o turismo, combinando atividades de cultura, lazer, shopping centers e habitações para a população de alta renda.

O "modelo" norte-americano influenciou a concepção política urbana britânica nos anos de 1980. O aparente renascimento econômico das cidades, cuja revitalização urbana supostamente as teria transformado em centros especializados no setor de serviços (Baltimore, Nova York, Boston, Pittsburg e Filadélfia), motivou a academia e o governo Thatcher a procurar reproduzir estas experiências na tentativa de reverter a acentuada decadência das zonas portuárias britânicas (COMPANS, 2004). O plano de revitalização das Docklands foi um sucesso, devido a uma crucial ajuda pública, transformando completamente a zona portuária de Londres. Ao mesmo tempo, os preços fundiários e imobiliários aumentaram vertiginosamente, atraindo cada vez mais investimentos e contribuindo para o contraste social e segregação espaciais entre as diferentes classes. A experiência das Docklands pôde mostrar que este modelo urbanístico conduzido pelo mercado pode ser ao mesmo tempo um sucesso comercial e um fracasso social. Fundada na estratégia de atrair investimentos privados com base em operações imobiliárias altamente rentáveis, acabou por gerar uma valorização excessiva que culminou na criação de verdadeiros enclaves territoriais de ricos (COMPANS, 2004).

A cidade de Barcelona sofreu sua reestruturação urbana por meio da realização dos Jogos Olímpicos de 1992, com um slogan de "abertura da cidade ao mar", extremamente propagandeado pela mídia, e um programa urbanístico da Villa Olímpica, o prolongamento da Avenida Diagonal até o mar e a renovação da foz do rio Besos, além da revitalização portuária construindo o complexo Maremagnum, com shopping, salas de cinema IMAX 3D e um aquário. O modelo de planejamento estratégico desenvolvido em Barcelona baseado em um programa de modernização e internacionalização da economia local. As intervenções previstas iam desde a reestruturação do sistema viário e 
o redescobrimento da fachada marítima-incluindo a reutilização das praias separadas da cidade por instalações industriais e portuárias- até construção de edifícios de escritórios e de apartamentos e a criação de parques e áreas verdes (COMPANS, 2004).

O modelo urbanístico foi fundado através da parceria entre setores públicos e privado, onde o poder público se instaurava por meio de convênios com empresas públicas, enquanto o setor privado era representado pelas parcerias entre os bancos espanhóis, empresas de construção e grupos internacionais do setor de serviços. Tal parceria foi alimentada pela especulação imobiliária, na qual os preços fundiários atingiram níveis absurdos que levaram a uma migração da classe pobre para a periferia. A dinâmica extraordinária da renovação urbana de Barcelona tomou uma grande repercussão, desenvolvendo assim o chamado "modelo Barcelona". Um exemplo de tal repercussão foi o modelo urbanístico adotado por Lisboa, que se configurou através de um megaevento a ser sediado pela cidade: a Expo'98. Foi uma grande operação urbana que não deixou de ser uma cópia da Villa Olímpica de Barcelona.

Tais estratégias utilizadas atracaram também na cidade do Rio de Janeiro para sua inserção na dinâmica do mercado mundial. Esse modelo utilizado para a execução dessa lógica empresarial aplicada ao espaço urbano também se desenvolveu como principal instrumento político de discursos, adequando-se às demandas necessárias para o "sucesso" da cidade, articulando a ação pública à privada e a uma lógica totalmente empresarial de venda da cidade por meio de projetos, dentre os quais o Projeto de Revitalização do Porto do Rio (Porto Maravilha).

\section{O Projeto Porto Maravilha como prática de (re) produção da segregação espacial}

A área que compreende a Zona Portuária do Rio de Janeiro ocupa 850,84 ha, e abriga uma população de 39.973 habitantes, de acordo com o censo de 2000 pelo IBGE. Os bairros da Zona Portuária guardam muitas marcas do início do 
século XX. Podem-se encontrar sobrados, galpões, e vilas operárias remanescentes do período industrial, edificações art déco e modernistas, que se misturam com os conjuntos habitacionais populares e às favelas, dando um aspecto de diversidade à área. Entretanto, também se predomina a obsolescência e o abandono causados pela perda da importância do Porto do Rio de Janeiro e da perda de valorização dessa localidade.

Para a implementação desse projeto, o city marketing cumpre importante papel de promoção da cidade mediante a construção e divulgação de uma imagem capaz de facilitar sua venda para possíveis investidores, e ao mesmo tempo, uma promoção da cidade para seus próprios habitantes, conferindo um novo significado às intervenções públicas, principalmente nas áreas centrais, no sentido a "produção do espetáculo". A "mobilização do espetáculo" para Harvey (1992) é o traço mais característico do urbanismo pós-moderno, sendo um símbolo e instrumento da unificação política, que tanto serviria à pacificação dos conflitos de classe quanto à competição interurbana pela atração de empresas e pelo consumo dos ricos. E assim, observando-se que enquanto os espaços públicos revitalizados transformados em grandes equipamentos coletivos de lazer transmitiriam o sentido do efêmero, da publicidade e do prazer transitório, os espaços privados articulariam o espetáculo e o consumo, por meio do individualismo e "privatopias". Desse modo, a cidade do Rio de Janeiro tornou-se uma "cidade vitrine", colocando a zona portuária carioca como uma de suas principais imagens de venda da cidade. Associada a ideia de sede dos megaeventos nos próximos anos (Copa do Mundo de 2014 e Olimpíadas de 2016) o discurso de revitalização de áreas degradadas se justificou e fortaleceu.

O projeto Porto Maravilha trata-se de uma operação urbana realizada pela parceria público- privada, envolvendo articulações de diversos grupos econômicos, visto que as transformações nas cidades envolvem atores sociais ligados aos setores imobiliário, de transportes, de turismo, de construtoras e de prestadoras de serviços de modo geral junto com o governo municipal, estadual e federal. Porém, destacam-se importantes impactos, que serão retomados futuramente, para a região, visto seu caráter mercadológico elitista. 
Como já mencionado anteriormente, a Zona Portuária do Rio de Janeiro permaneceu por um tempo à margem da cidade devido à verticalização da área central, permitindo a cristalização de suas formas e atividades consideradas tipicamente cariocas. Em consequência de sua relevância histórica, no início da década de 1980 foi implementado um projeto de preservação desse patrimônio, o Projeto SAGAS. Além de contar com bens imóveis tombados pelo Instituto do Patrimônio Histórico e Artístico Nacional IPHAN. Dentre suas principais atribuições, ressalta-se:

- a manutenção das características consideradas importantes na ambiência e identidade cultural da área;

- preservação dos bens culturais que apresentem características morfológicas típicas e recorrentes na área;

- estabelecimentos de critérios para novos gabaritos;

- prévia aprovação para demolições e construções;

- criação de um escritório técnico, para fiscalização e acompanhamento das intervenções.

O abandono por parte do poder público devido à perda de seu valor especulativo em tempos pretéritos permitiu um uso predominantemente residencial, visto que a proporção para este uso, segundo o Instituto Pereira Passos $(2009)^{3}$, corresponde a $51,28 \%$ e para fins não-residenciais corresponde a $48,72 \%$. As moradias, em geral populares, abrangem um número considerável de cortiços e ocupações de grupos sem-teto. Além do fim residencial, a Zona Portuária abriga um conjunto de atividades econômicas que dinamizam o espaço e a circulação local. Dentre as atividades desenvolvidas, foi possível perceber certa homogeneidade em sua distribuição, variando o número de unidades comercias entre 75,0\% (Saúde) e 69,4\% (Gamboa); e os de serviço entre 25,0\% (Saúde e Santo Cristo) e 22,4\% (Gamboa) (Gráfico 1).

\footnotetext{
${ }^{3}$ Consulta ao site do IPP : http://www.rio.rj.gov.br/ipp/ consultado em junho de 2012.
} 


\section{Gráfico 1: Estabelecimentos por tipo de atividade e bairro (\%)}

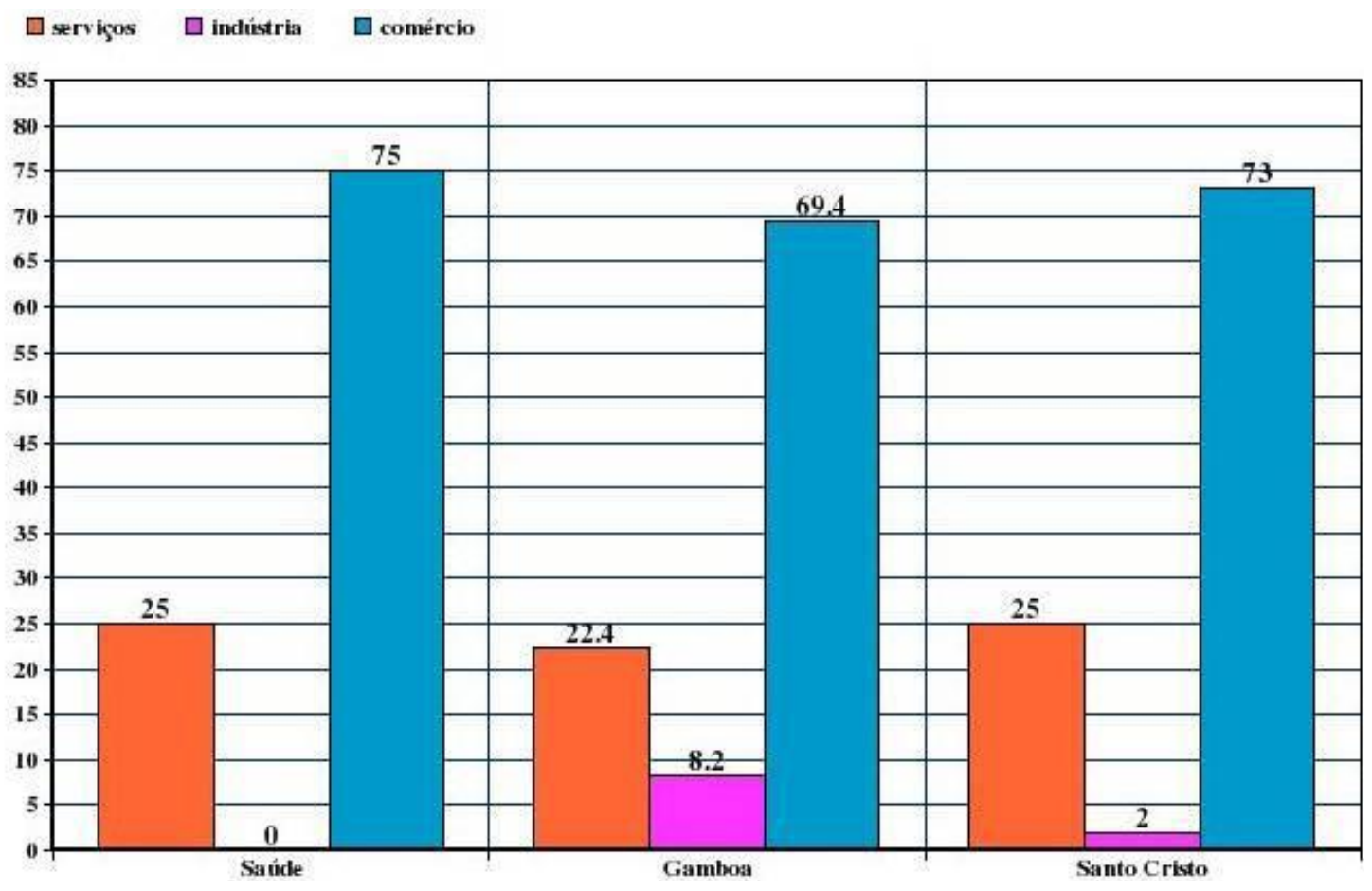

Fonte: Instituto Pereira Passos - IPP (2009)

A partir do gráfico acima (Gráfico 1) é possível observar a importância do comércio para a localidade, pois abriga uma grande quantidade de estabelecimentos comerciais. Estes estabelecimentos compreendem pequenas oficinas e lojas, e uma grande quantidade de estabelecimentos informais (camelôs), pontuando mais uma característica da predominante população habitante de baixa renda e sua função para o desenvolvimento de pequenas atividades comerciais.

Outro dado importante para denominar o perfil da população afetada pelas obras do Projeto Porto Maravilha é sua escolaridade, onde a grande maioria cursou apenas a primeira parte do Ensino Fundamental, não o concluindo $(44,7 \%)$. Os que cursaram todo o Ensino Fundamental somam $15 \%$, enquanto os que completaram o Ensino Médio constituem 19,8\% dos moradores. Já os analfabetos correspondem a 2,7\% da população local (Gráfico 2). Este importante dado nos mostra que devido a baixa escolaridade, a grande maioria dos moradores não sabem, reconhecem ou lutam pelos seus direitos a participação nos debates a respeito das intervenções, sendo alvos fáceis para 
a alienação do Estado através de falsas propagandas de melhorias de vida para essa população e mais vulneráveis ao processo de expulsão.

\section{Gráfico 2: Escolaridade dos moradores, por bairro (\%)}

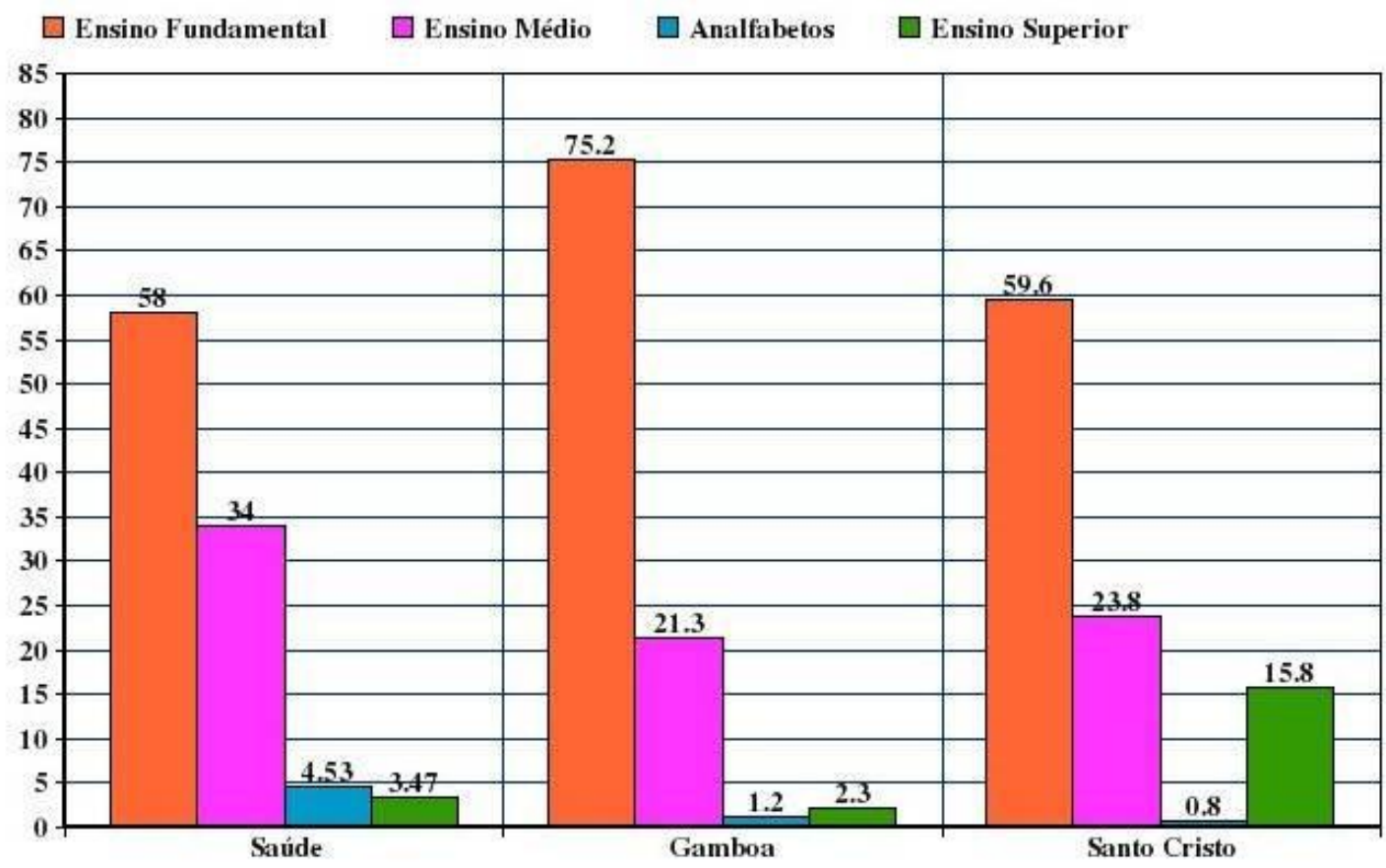

Fonte: Instituto Pereira Passos-IPP (2009)

No que tange aos rendimentos dos moradores, a maioria não possui carteira assinada, não ganhando as vantagens como férias remuneradas, $13^{\circ}$ salário e FGTS. O ganho médio dos trabalhadores situa-se entre 1,0 e 3,0 salários mínimos (72,4\%). Em seguida sobressai a faixa dos que recebem entre 3,01 e 5,0 salários mínimos (14\%) (Gráfico 3). Portanto destaca-se o baixo rendimento da população. 
Gráfico 3: Rendimento dos moradores por bairro (\%)

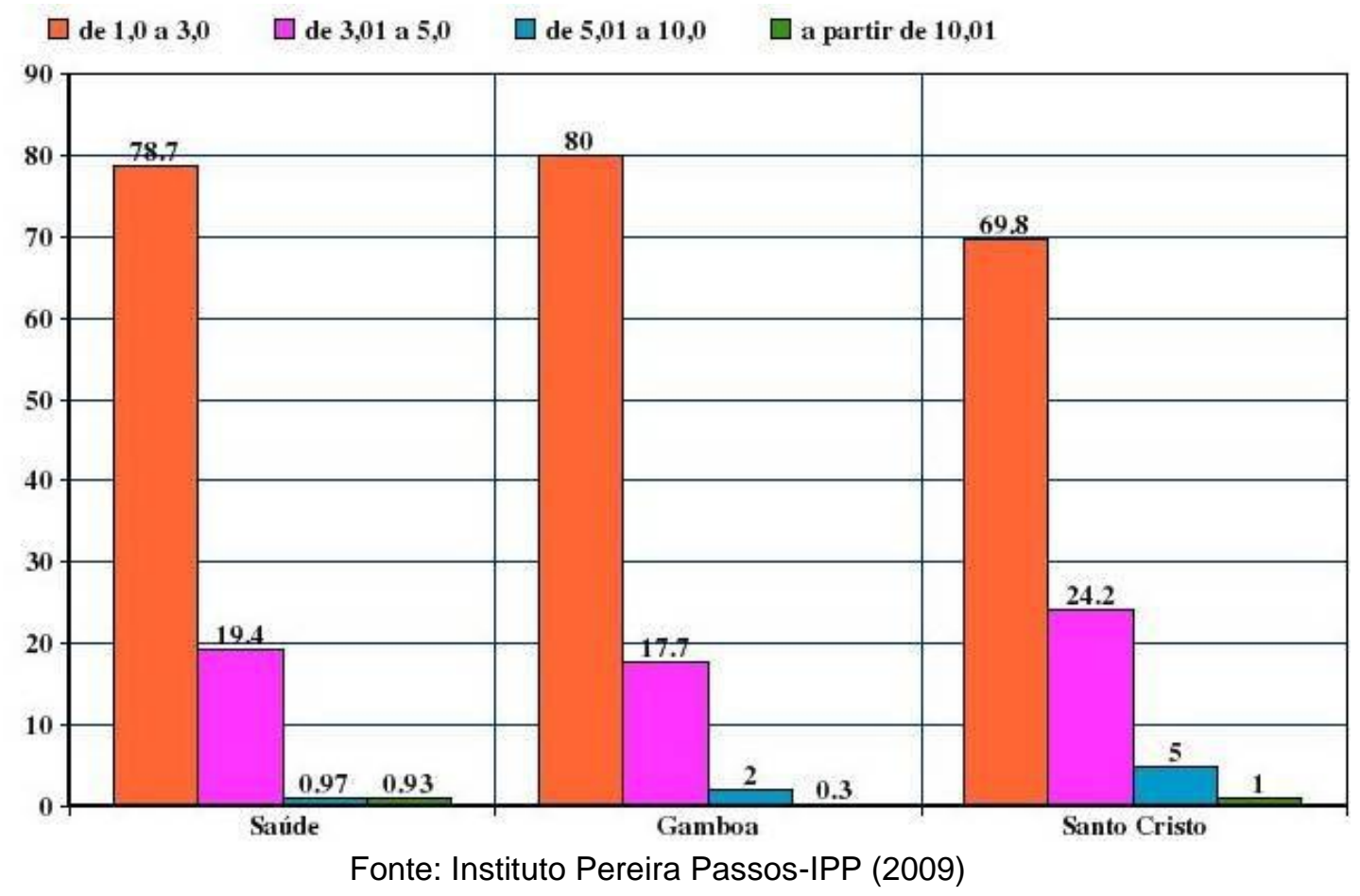

A partir dos dados acima, que configuram o perfil da Zona Portuária do Rio de Janeiro, é possível traçar um panorama dessa localidade para se compreender o que realmente as intervenções urbanísticas pretendem, e simultaneamente projetarmos as consequências para os moradores e as pessoas que apenas ali trabalham muitos deles provenientes da Baixada Fluminense. E assim observar-se que qualquer proposta de intervenção deveria ser fruto de intensos debates e participações da comunidade local e da cidade como um todo para que não caísse em um processo de exclusão social.

Outro ponto fundamental para percebermos como a segregação espacial, e consequentemente social, está se configurando na Zona Portuária do Rio é o estudo do chamado Projeto Porto Maravilha, procurando entender sua proposta de rearranjo espacial para a área, seus parceiros e discurso. $O$ projeto foi lançado em um evento que contou com a participação de políticos e empresários, que juntos anunciaram uma grande reestruturação urbana, visando à construção do patriotismo de cidade e criar um clima de credibilidade para com os potenciais investidores. 
Dentre as obras anunciadas temos a derrubada de uma parte do Elevado da Perimetral (entre o Mosteiro de São Bento e a Rodoviária Novo Rio) e a mudança do ponto de atracação dos navios de turismo. Além de ações que evidenciam os altos investimentos públicos e privados, como por exemplo, a construção do Museu do Amanhã no Píer Mauá e a instalação do Museu de Arte do Rio de Janeiro através da recuperação de dois imóveis localizados na Praça Mauá. Os dois museus contam com a parceria com a Fundação Roberto Marinho e seus custos de cerca de 150 milhões de reais divididos entre a Prefeitura e a União. Além da reurbanização de $70 \mathrm{~km}$ de vias e $650.000 \mathrm{~m}^{2}$ de calçadas, a reconstrução de $700 \mathrm{~km}$ de redes de infraestrutura urbana (água, esgoto, drenagem) e a urbanização do Morro da Conceição, juntamente com a restauração do Jardim Suspenso do Valongo necessárias para a constituição de um grande pólo turístico,comercial e residencial, ao mesmo tempo em que altera o perfil socioeconômico local atraindo uma população de médio à alto teor aquisitivo e bem instruídas, diferentemente dos dados que representam os moradores da Zona Portuária aqui já mencionados.

A segunda etapa do projeto corresponde ao plano imobiliário. Para essa etapa foram disponibilizados 34 milhões de reais das instituições Federal e Municipal e a venda dos "Certificados de Potencial Adicional de Construção" (CEPAC), títulos que darão aos empreendedores direitos construtivos gerados por modificações na lei, podendo construir acima do permitido, onde vale destacar que tais títulos foram comprados pela Caixa Econômica Federal, mostrando assim um investimento público maior e de maneira exacerbada para a promoção desse projeto que será extremamente proveitoso para o setor privado. Dentre os beneficiados com essa "brecha" na lei está a Construtora Odebrecht que instalou o chamado Porto Atlântico, empreendimento para a venda de torres com lajes corporativas, salas comerciais, lojas e suítes hoteleiras. Construtora responsável também por grande parte das intervenções urbanísticas propostas pelo projeto, deixando desvelar os primeiros resquícios que mostram a verdadeira face dessa política de requalificação. Portanto, do ponto de vista em que se efetua o projeto é possível perceber o seu uso para a transformação do Rio de Janeiro numa cidade global e para uma maior dinamização dos fluxos de capitais. 
É possível também constatar nesse cenário que envolve toda essa política de reabilitação um caráter publicitário, criando uma imagem absolutamente tendenciosa da cidade e do próprio projeto por meio de seus canais de comunicação apresentando imagens e magníficas projeções em 3D, que ajudam a manipular o imaginário da população sobre a Zona Portuária. Mas essa estratégia também mostra sua face de ameaça ao modo de vida e identidade dos moradores por meio do discurso do nascimento de uma nova área, onde o indivíduo não se vê nesse lugar impessoal, que perdeu os traços que ajudaram a construir todo um sentimento de pertencimento e acolhedor característico da Zona Central do Rio de Janeiro, transformando-o em um espaço que produz uma intensa seletividade social.

Deste modo, apesar de se tratar de um processo recente e ainda existir questões que se encontram em aberto neste artigo, é possível auferir algumas considerações.

Em primeiro lugar podemos observar que a partir do desvelamento da verdadeira política adotada pelo Estado carioca e das experiências anteriores utilizadas como modelos, onde os autores permitiram o avanço da discussão desenvolvida, nos mostram que essas "intervenções urbanísticas revitalizadoras" geram o aumento da segregação espacial e das tensões sociais, visto que o território não é um espaço neutro e que tais processos trazem consigo intencionalidades hegemônicas.

Outra consideração a ser apresentada corresponde as principais ações e objetivos do Projeto de Revitalização do Porto do Rio, podendo-se observar o seu interesse em produzir novas seletividades e afastamentos sociais por meio da produção de espaços especulativos para interesses privados, nos quais os espaços públicos tornam-se meros resquícios na cidade, ao mesmo tempo em que tudo se mercadifica. Através desses fatores, as atividades e o modo de vida local serão alterados, devido a sua banalização e transformação em "mercadoria cultural" para a atração de novos empreendimentos econômicos e do turismo, levando ao fechamento dos pequenos estabelecimentos que caracterizam a região. 
Por último, destaca-se a especulação imobiliária, promovida pela intervenção urbana, haja visto a valorização em $300 \%$ do metro quadrado da região e projeção do preço do aluguel entre $14 \mathrm{mil}$ a 20 mil reais para os novos empreendimentos (Associação de Dirigentes de Empresas do Mercado Imobiliário - ADEMI), apontando para a impossibilidade dos moradores atuais se manterem e sua consequente expulsão. Além das remoções forçadas, muitas realizadas de forma grosseira, sem nenhum aviso prévio para os moradores encontrarem outro lugar para morar ou, ao menos, retirarem seus pertences, ferindo assim seu direito à moradia e ao habitar.

\section{Considerações finais}

Viemos relatando acerca das transformações pelas quais vêm passando as cidades, onde o Rio de Janeiro se coloca atualmente como incorporadora dessa dinâmica, procurando discutir sobre o processo que tem contribuído para consideráveis mudanças nas formas de pensar, gerir e produzir as cidades. Mais do que falarmos em uma sociedade urbana, importa pensarmos no processo de metropolização do espaço. Trata-se de um processo que imprime ao território características que até então eram exclusivas da metrópole, ou, em alguns casos, da região metropolitana (LENCIONI, 2013). Nesse sentido, não só as práticas espaciais, mas também as identidades dos lugares ficam sujeitas aos códigos metropolitanos. Acredita-se que o processo de metropolização do espaço guarda ligação com o discurso da associação entre modernização, progresso, desenvolvimento e homogeneização. Porém, essa tendência à homogeneização não se realiza sem tensões, sem conflitos. A metropolização do espaço leva-nos a considerar a multiplicidade e a enorme intensidade dos fluxos de pessoas, de informação e de mercadorias. Ademais, não devemos esquecer que cada vez mais tudo tem se transformado em mercadoria.

A sustentação desse trabalho está ancorada em importantes categorias e conceituações, tais quais estrutura social, econômica e cultural; reprodução das relações sociais; representações; metropolização do espaço; a racionalidade (em geral distante do lugar); o direito à cidade (com o pensamento alternativo de alternativas); a igualdade (conduzida pela luta pelo 
reconhecimento da diferença); homogeneização, fragmentação e hierarquização; as escalas (mais especificamente a transescalaridade); presentificação, resistências (mobilizações sociais, em um sentido mais amplo); e, finalmente, desenvolvimento(s).

É preciso, também, contestarmos a maneira pouco cuidadosa pela qual ainda é utilizada a palavra desenvolvimento; que força tem essa expressão! Praticamente tudo é permitido se for em prol do desenvolvimento. Esse discurso do desenvolvimento tem sido crucial para o desenho da própria identidade do país, pois ao longo do tempo foi amplamente difundida a ideia de que é preciso se desenvolver; é preciso ser moderno. Com isso, muitos países viveram e vivem uma modernização ilusória com padrões de consumo imitativos, sem vínculo com as reais necessidades da sociedade. A população desses países tem experimentado a modernidade como uma ameaça a toda a sua história, tradições e objetivos. O desenvolvimento é concebido como item da modernidade vista assim como modernização. Progresso e modernidade são conceitos que acompanham o desenvolvimento fazendo-se forte ideologicamente. Deste modo, tem-se, ainda hoje, utilizado desenvolvimento como sinônimo de crescimento econômico. Esse crescimento, definitivamente, não impede o aniquilamento da sociedade, pois não se trata apenas de desigualdades de desenvolvimento, mas da total destruição das relações sociais. Na verdade, quando há luta, ela se resume a ter condições menos ruins; nunca se refere à luta pela dissolução do modelo de exploração. Ou seja, não há busca pela mudança radical.

A racionalidade econômica tende a estender-se a toda a sociedade, assim 0 lugar da reprodução das relações de produção é também o cotidiano do trabalho e do lazer, que se encontra extremamente ligado ao consumo; ou seja, os tempos livres são cada vez mais comercializados. Não estamos mais nos referindo à reprodução dos meios de produção, mas da reprodução das relações de produção. Em outras palavras, o que se fez durante muito tempo foi a análise crítica da produção e da reprodução dos meios de produção; quer dizer, das forças produtivas - ou seja, os trabalhadores e os seus instrumentos de trabalho. O que significa que os trabalhadores têm de reproduzir-se; de forma mais clara significa dizer que precisam ter filhos, alimentá-los, educá-los 
e torná-los capazes de trabalhar. Além disso, no que tange às máquinas e instalações, há o desgaste, transmitindo o seu valor, calculado em dinheiro, aos produtos. Contudo, segundo Lefebvre (1973), ainda mais importante do que isso, as técnicas e a maquinaria transmitem-se à organização e à divisão do trabalho; e desde então já estamos tratando da base da reprodução das relações sociais. O que está se querendo dizer é que não mais o discurso econômico, mas o próprio cotidiano tornou-se a base sobre a qual 0 capitalismo se estabelece.

A consciência vai perdendo sua função ativa à medida que o processo de reificação penetra nos setores não econômicos do pensamento e da própria afetividade, isto porque esse conjunto econômico tende a se apossar de todas as manifestações da vida humana. Goldmann (1977, p. 141) lembra-nos que, em muitos textos, "Marx insiste no fato de que (...) o que caracteriza o valor de troca é que ele transforma a relação entre o trabalho necessário à produção de um bem e este mesmo bem em qualidade objetiva do objeto; é o próprio processo de reificação". Assim, estamos falando de um processo social que faz com que o valor chegue à consciência da sociedade como uma qualidade objetiva da mercadoria. Importa percebermos que um dos pontos fundamentais da sociedade capitalista é mascarar as relações sociais entre os homens, transformando-os em seres passivos:

Em espectadores de um drama que se renova continuamente e no qual os únicos elementos realmente ativos são as coisas inertes. [...] Substitui valor de uso por valor de troca e as relações humanas concretas [e específicas] por relações abstratas e universais entre vendedores e compradores (GOLDMANN, 1977, p. 145).

E mais, separa o produto do produtor, contribuindo para a imobilização, para a naturalização e banalização das desigualdades; não há alternativa é a expressão mais ouvida.

O espaço torna-se cada vez mais o meio de reprodução das relações sociais; sendo hierarquizado, objeto de investimentos públicos e privados, reserva de valor ou mesmo deixado ao acaso e abandonado. Talvez a grande batalha deva centrar-se na necessidade de romper com a ocultação e buscar desvelar essa dominação do espaço. Lefebvre (1973, p. 96) acrescentava, já na década de 1970, que "os espaços de lazer constituem objecto de especulações 
gigantescas, mal controladas e frequentemente auxiliadas pelo Estado (construtor de estradas e comunicações, aval directo ou indirecto das operações financeiras, etc.)". O espaço é vendido a alto preço aos citadinos e outros são "expulsos" de certas áreas da cidade. Na maioria das vezes, essa "expulsão" se dá de forma indireta, visto que o aumento do custo do solo urbano no lugar inviabiliza a permanência da população de mais baixa renda. Há vários estudos acerca das políticas de "revitalização" e/ou "renovação" urbana e a consequente gentrificação, entretanto, neste estudo se procurou mostrar como as novas tecnologias de informação e comunicação têm modificado a maneira de vender, viver e experimentar a cidade, contribuindo para que acreditemos que o mundo está cada vez mais acelerado.

Tratamos da utilização da imagem da cidade por meio do city marketing como estratégia para ocultar as tensões na produção do espaço. É a partir deste cenário que procurou desvelar as estratégias de produção do espaço à revelia dos habitantes do lugar a partir da construção, no imaginário social, de ideários de cidade, que vão ao encontro do desejo dos proprietários fundiários, dos promotores imobiliários e do empresariado e que tem tido como resultado, graves processos de gentrificação.

Com relação às obras, associadas aos novos empreendimentos que serão e outros que já estão sendo construídos na Zona Portuária do Rio de Janeiro, destaca-se uma nova função para a área em apresentada e a perda da vida social de boa parte dos atuais moradores, pois se tornará uma área de prédios luxuosos e de grandes empreendimentos que sufocarão a ideia de cidade como lugar das relações sociais, substituindo-a pela a ideia de cidade como lugar das relações comerciais.

Portanto, este modelo de zona portuária que não é inédito, por já ter ocorrido em outras cidades, nos leva a concluir que o que existe é um processo de "homogeneização metropolitana". As cidades como Baltimore, Londres, Barcelona e Lisboa mostram uma convergência urbanística entre elas e para com a cidade do Rio de Janeiro, apresentando seus centros histórico-culturais, portos e modo de vida local em marinas e centros de cultura, lazer, aquários públicos, edifícios de escritório e moradias para as classes de alta renda da sociedade. A combinação é a mesma: investimentos públicos e privados para a 
construção de novos equipamentos culturais e de serviços, a criação de uma área pública junto ao mar e empreendimentos de moradia e financeiros próximos. Vale ressaltar que esta parceria é algo muito teórico, pois a realidade da revitalização da Zona Portuária carioca permitiu observar que as empresas privadas é que ditam a lógica dos projetos, sobrando para o poder público os riscos.

\section{Referências}

COMPANS, R. Intervenções de recuperação de zonas urbanas nas centrais: experiências nacionais e internacionais. EMURB. Ação para o Centro de São Paulo. EMURB, 2004.

FERREIRA, A. A cidade do século XXI: segregação e banalização do espaço. Rio de Janeiro: Consequência, 2011.

GOLDMANN, L. A reificação das relações sociais. In: FORACCHI, M. M.; MARTINS, J. S. Sociologia e Sociedade: leituras de introdução à Sociologia. Rio de Janeiro: LTC, 1977.

HARVEY, D. A condição pós-moderna. São Paulo: Loyola, 1992.

LENCIONI, S. Metropolização do espaço: processos e dinâmicas. Conferência de abertura I SIMEGER, mimeo, 2013.

LEFEBVRE, H. A reprodução das relações de produção. Porto, Portugal: Escorpião, 1973.

SÁNCHEZ, F. A reinvenção das cidades na virada de século: agentes, estratégias e escalas de ação política. Revista de sociologia política, Curitiba, n. 16, p. 31-49, jun. 2001.

SÁNCHEZ, F. A reinvenção das cidades para um mercado mundial. ChapecóSC: Argos Editora Universitária, 2003. 